\title{
A COURSE OF \\ PURE MATHEMATICS
}

By G. H. HARDY

Seventh Edition. Revised and Reset. 12s. $6 d$. net

In this edition important changes have been made and the book has been reset. The contents of Appendix II have been incorporated in the appropriate places in the text. The parts of Chapters VI and VII which deal with the elementary properties of differential coefficients have been rewritten, and a large number of new examples from the papers for the Mathematical Tripos during the last twenty years have been inserted.

British Association for the Advancement of Science

\section{MATHEMATICAL TABLES VOLUME VI BESSEL FUNCTIONS}

\section{PART I. FUNCTIONS OF ORDERS ZERO AND UNITY} 40s. net

Prepared by the Committee for the Calculation of Mathematical Tables.

\section{FREQUENCY CURVES AND CORRELATION}

\author{
By SIR W. PALIN ELDERTON
}

Third Edition. 12s. 6 d. net

Originally published by C. and E. Layton, Limited, this work is now a standard textbook on curve-fitting and has been several times re-issued. In this new edition the author has made many alterations and has rewritten the chapters on Standard Errors, The Test of Goodness of Fit, and The Correlation Ratio-Contingency.

\section{QUALITATIVE INORGANIC ANALYSIS}

\section{By A. J. BERRY}

6s. net

This book, by the author of "Volumetric Analysis," takes account of new methods and conditions, and makes two radical departures from tradition: in the first place, the author has broken down the artificial distinction between the "common" elements and some of the "rare" elements, since many of the latter are now of great industrial importance; secondly, the use of a number of new reagents, particularly some organic compounds, is included for "spot tests," in order to acquaint the student with the rapid progress made in the way of applying new reagents and with the modern technique of analysis.

\section{CAMBRIDGE UNIVERSITY PRESS}




\section{O N T E N T S}

Du VAL, Patrick. The fixed part of the canonical system on an algebraic surface

EDGE, W. L. Determinantal representations of $x^{4}+y^{4}+z^{4}$

BABBAGE, D. W. The resolution of monoidal Cremona transformations of threedimensional space . . . . . . . • • • • • .

Davenport, H. Note on an identity connected with diophantine approximation . . . . . . . . . . . . . . 27

ERDÉLyI, A. The Hankel transform of Whittaker's function $W_{k, m}(z) \quad$. $\quad 28$

BANERJI, D. P. The expansion of an arbitrary function in a series of conal or toroidal functions . . . . . . . . . . . . 30

BARTLETT, M. S. Further aspects of the theory of multiple regression . . 33

Segal, Irving E. Fiducial distribution of several parameters with application to a normal system

GoLdstern, S. On the velocity and temperature distributions in the turbulent wake behind a heated body of revolution. (With 6 Figures in the Text) .

EASTHOPE, C. E. The critical ordering temperature in alloys. II. The existence of a two-phase region. (With 5 Figures in the Text) . . . .

WiLson, A. H. Lattice changes associated with the formation of superlattices in alloys.

TrBBs, S. R. Electronic energy bands in metallic copper and silver. (With 5 Figures in the Text)

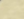

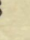

Fuchs, K. The conductivity of thin metallic films according to the electron theory of metals. (With 2 Figures in the Text) . . . . . 100

SkINNER, H. W. B. and Johnston, J. E. Soft X-ray bands from dilute alloys. (With 4 Figures in the Text) • • . . . . . . 109

Feather, N. Note on the absorption limits for the primary $\beta$-particles of mesothorium 2 and uranium $\mathrm{X}_{2}$. (With 1 Figure in the Text). . $\quad 115$

StAnSFIELd, R. G. A search for ionization of hydrogen by diffusion through palladium. (With 1 Figure in the Text) . • • . • • 120

\section{LONDON: CAMBRIDGE UNIVERSITY PRESS}

INDIA: MACMILLAN

TOKYO: MARCZEN COMPANY LIMITED

\section{Dutch Photo Reprint}

